\title{
Sudden infant death syndrome and environmental temperature: an analysis using vital statistics
}

\author{
M F G MURPHY AND M J CAMPBELL \\ From the Medical Statistics Division, OPCS, London; and Department of Community Medicine and Medical \\ Statistics, University of Southampton
}

SUMMARY We examined the relation between the daily numbers of deaths ascribed to sudden infant death syndrome (SIDS) $(n=6226)$ and daily temperature in England and Wales over the five year period 1979-83. When the data were filtered to remove the dominant seasonal trend, and residual autocorrelation, we found a significant negative correlation of deaths with both the level and rate of change of temperature four to six days earlier, irrespective of age at death. Place of usual residence was obtained for 909 SIDS cases occurring during the unusually severe winter of 1981-82, and, using space-time clustering techniques, we confirmed previous findings of the lack of 'epidemicity' for this condition. These results are compatible with several previous hypotheses of the relation between the weather and SIDS and directly incriminate drops in temperature in the occurrence of the condition.

The general epidemiological features of the sudden infant death syndrome (SIDS) are well described. ${ }^{1}$ They are remarkably consistent for a condition that is diagnosed by exclusion, and whose aetiology is controversial. One very characteristic feature of these infant deaths is that in both northern and southern hemispheres SIDS exhibits marked seasonal variation, although whether this is equally true of deaths occurring above and below the age of 3 months is disputed. Of the many hypotheses of the cause of SIDS, important contenders to explain this winter excess, broadly consistent with the other major epidemiological features, include associated upper respiratory tract infections, exposure to low environmental temperatures or, somewhat paradoxically, overheating. ${ }^{2}$

This characteristic winter excess of SIDS was unusually pronounced in the first quarter of 1982 in England and Wales. The increase was sufficiently large for the postneonatal mortality rate in 1982 to rise above the 1981 level before falling again. ${ }^{34}$ Inspection of the Office of Population Censuses and Surveys (OPCS) data revealed that there had also been a large number of SIDS deaths in the last quarter of 1981 . Although this peak was not apparent in Scotland, this death toll was the highest in England and Wales since 1971 when the term SIDS came into general use as a cause of death, and it coincided with an unusually severe winter. The rise was not due to an increase in births in 1981 affecting the numbers of infants at risk, did not appear to be an artefact of changing fashions of certification whereby the diagnostic label SIDS has been increasingly used since 1971 , and was apparent over all England and Wales. Data obtained from the Communicable Diseases Surveillance Centre, which monitors the level of laboratory confirmed infection, showed that by comparison with the winters of 1980-1 and 1982-3 there was no plausible relation between the pattern of SIDS deaths and any apparent viral epidemics, with the possible exception of rotaviruses. This association between an increase in SIDS cases and a severe winter suggested again the need to investigate the importance of temperature in the occurrence of SIDS.

\section{Methods}

Since 1971 it has been OPCS practice to identify not only deaths where the underlying cause was coded to SIDS (795 ICD 8, 798.0 ICD 9) but also those deaths where another underlying cause has been certified but the phrase 'sudden infant death', or similar, is mentioned somewhere on the certificate. Statistics on SIDS are routinely published in this way, and it has been believed that this practice more accurately reflects the toll of SIDS. ${ }^{5}$

Daily occurrences of these 'total SIDS mentions' and their age at death were extracted for the continuous period' January 1979 to 31 December $1983(n=6,226)$. For those deaths occurring during the winter of 1981-2 $(n=911)$, place of usual residence was also ascertained. In the analysis, deaths up to 3 
months of age and deaths between 3 months and 1 year were considered separately. The period $1979-83$ was chosen to include several seasonal cycles and mild/ moderate winters. We also felt that fashions in use of the term SIDS were more likely to have been relatively stable over the recent past than when the term was first introduced. Daily maximum and minimum temperatures (as well as rainfall and sunshine data), measured at the London Weather Centre, were obtained from the Meteorological Office for the same continuous period of 1826 days.

Before undertaking a time-series analysis of the deaths and temperature, we tested for space-time clustering of the 909 SIDS cases occurring between 1 October 1981 and 31 March 1982; two cases were excluded because they were not usually resident in England and Wales. Two methods were used: the 'close-pairs' method of Knox 6 and the 'sum of empiric clusters' method of Ederer-Myers-Mantel. ${ }^{7}$ For the first of these the map grid reference of address of usual residence was obtained and the number of pairs examined over a wide range of time and distance values. Using the Ederer-Myers-Mantel method, we subdivided England and Wales into five areas of approximately equal size and compared the numbers of deaths in each sub-area over five intervals of four weeks. In addition, simple time-clustering was tested using the approximate method of Knox and Lancashire. ${ }^{8}$
When correlating two time series, it is important to filter out dominant trends and serial correlation within each series. Failure to do this can lead to potentially misleading correlations. For example, there is a strong positive correlation between the annual number of storks nesting in Holland and the birth rate, but correlation does not necessarily imply causation However, if short term fluctuations in one series are consistently followed by short term fluctuations in the other, then causation becomes more plausible.

Because the daily data have a highly skewed distribution, the numbers of deaths on each two consecutive days were pooled. The temperatures for the first day were used and the square root of the deaths was taken to stabilise the variance. The principal technique involved fitting separate harmonic models of the form $y_{t}=a \cos (w t-b)+c$ (with $w=2 \pi / 365$ and $a, b$ and $c$ allowed to vary from year to year) to the deaths and temperature data for each year. ${ }^{9}$ The phase of each sinusoid was estimated by $b$, and the temporal relation between the peaks of deaths and troughs of temperature was thus assessed. This is illustrated schematically in figure 1 . Then, having removed the dominant seasonal trend as a sinusoid from both the death and temperature series, we used Box-Jenkins' ${ }^{10}$ autoregressive moving average model as necessary to remove any remaining autocorrelatiox within each series. Finally, the cross-correlatio between the residuals of temperature and deaths wad

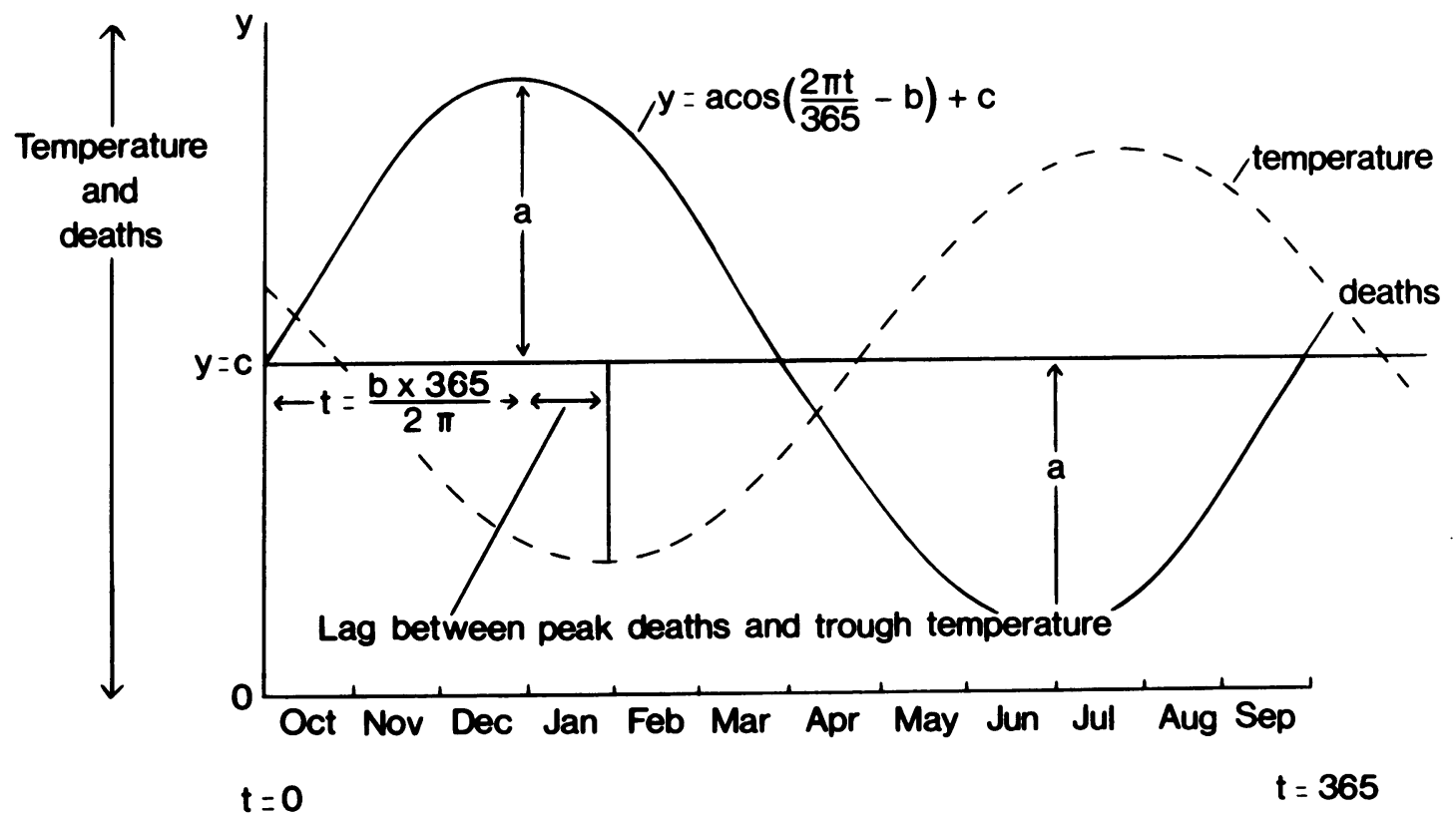

Fig 1 Schematic diagram of the relation between SIDS deaths and temperature throughout the year 
calculated. Here the extent of correlation of the daily 'background noise' variation of the levels of both temperature and deaths rather than their dominant seasonal fluctuation is the object of interest. ${ }^{11} \mathrm{~A}$ supplementary analysis of the phase relation between the series was carried out using cross-spectral analysis ${ }^{9}$ to corroborate the analysis described above.

In addition, we looked at the relation between deaths, rainfall, and sunshine over the six months 1 October 1981 to 31 March 1982. The dominant seasonal component was removed from both series as a quadratic trend, Box-Jenkins modelling was used to remove residual serial autocorrelation as above, and the cross-correlation function between the residuals was calculated.

\section{Results}

FIVE YEAR PERIOD I 979-83

The mean daily temperature and daily deaths $1979-83$ in England and Wales are shown in fig 2 with the best fitting sinusoids. There were 6226 deaths in that time, an average of 3.41 deaths per day (SD 2.29). The coefficient of skewness of the original data was $0 \cdot 84$, whereas that of the pooled square-rooted data was $-0 \cdot 26$. Having removed the seasonal component of the variation, both the temperature data and the deaths were modelled by low order autoregressions with a maximum lag of 3 . All models satisfied the usual goodness-of-fit criteria. ${ }^{9}$ Figure 3 indicates the extent of residual cross-correlation between the daily
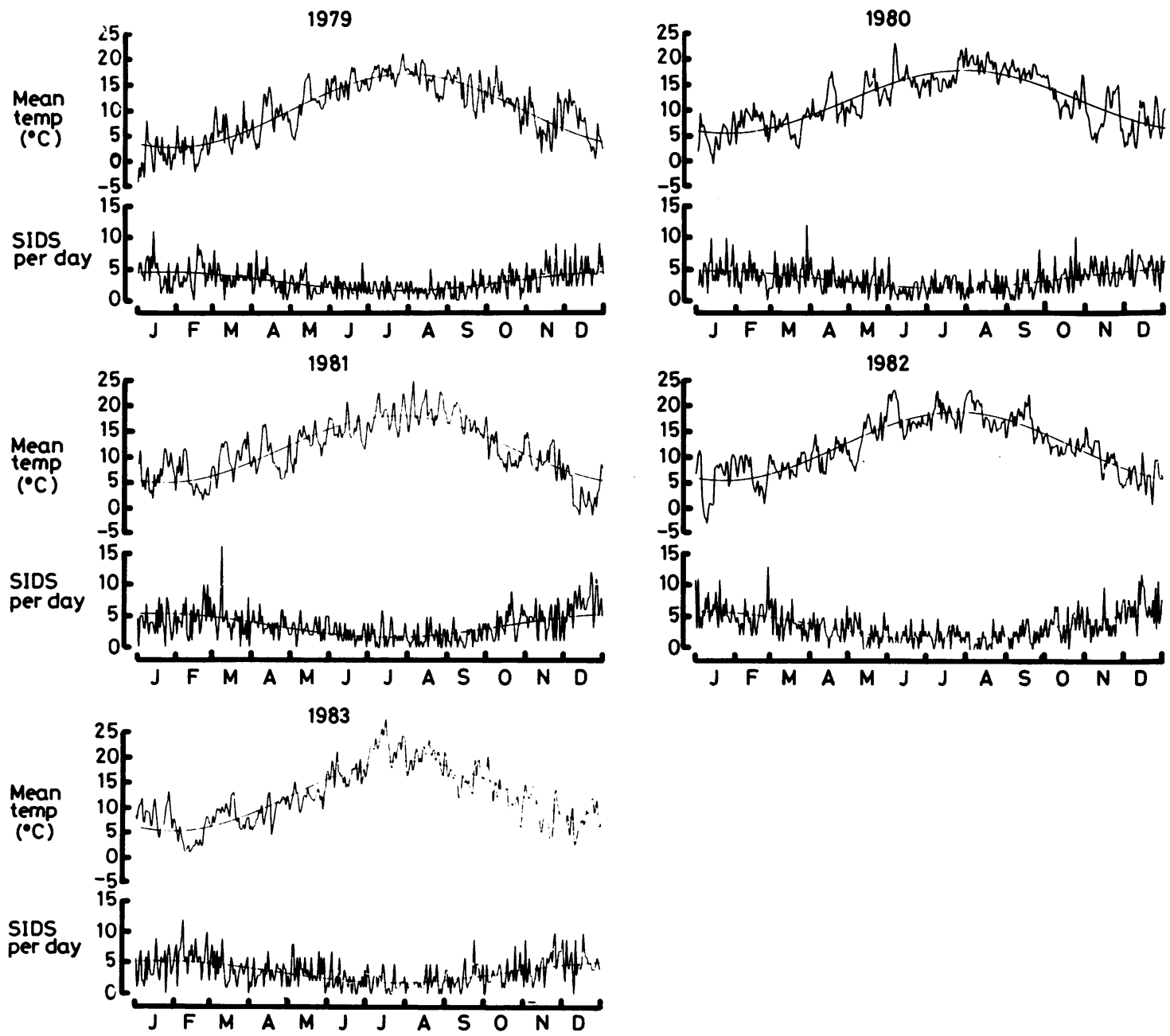

Fig 2 Mean daily temperature and daily occurrences of SIDS 1979-83. 


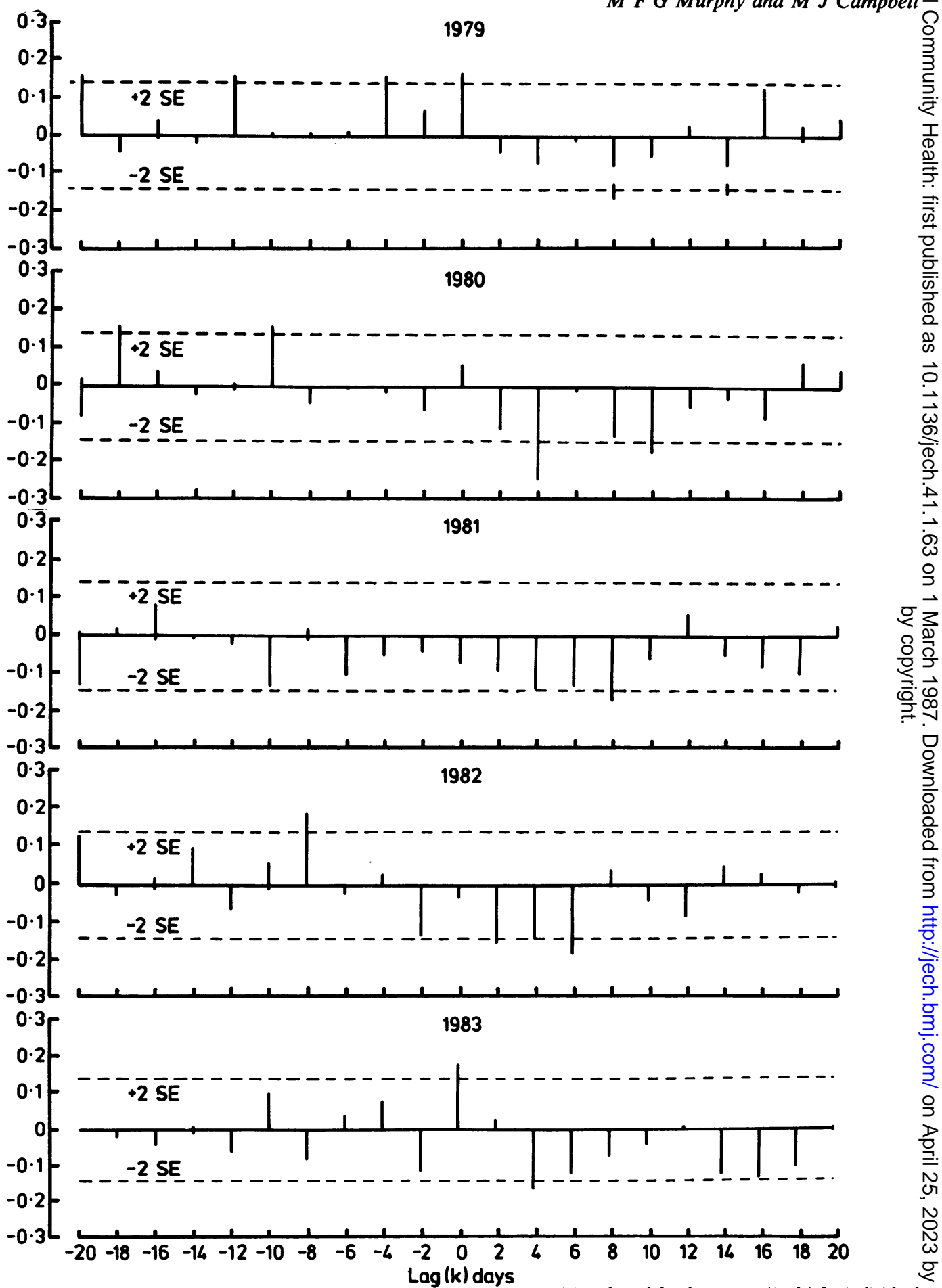

Fig 3 Cross-correlation of the residuals of maximum daily temperatures at time ( $i$ ) and total deaths at time $(i+k)$ for individual 0 years 1979-83. 
Sudden infant death syndrome and environmental temperature: an analysis using vital statistics

maximum temperatures and deaths after the dominant seasonal trends have been removed from both series. For each of the five years there is a modest but persistent negative correlation between temperature and deaths occurring two to six days later. Figure 4 shows that, in aggregate this correlation is highly significant for maximum and minimum daily temperatures alike. While cross correlations at other lags are significant within some of the years, no other consistent relation between the series was found. The findings were very similar when both early deaths (under 3 months) and late deaths (over 3 months) were analysed separately.
For each year the residuals for deaths and temperature were plotted against one another, with deaths lagging temperature by four days. Inspection of the graphs revealed the negative correlation, with no evidence of any asymmetry $\left(x_{1}^{2}=1.66, p>0.3\right)$, ie, low temperatures were followed by an increase in deaths and high temperatures by a fall in deaths, four days later.

In a separate modelling exercise we examined whether the results hold true equally in summer and winter. Having filtered out the seasonal differences, we found little evidence that the correlation between temperature and death was significantly stronger in

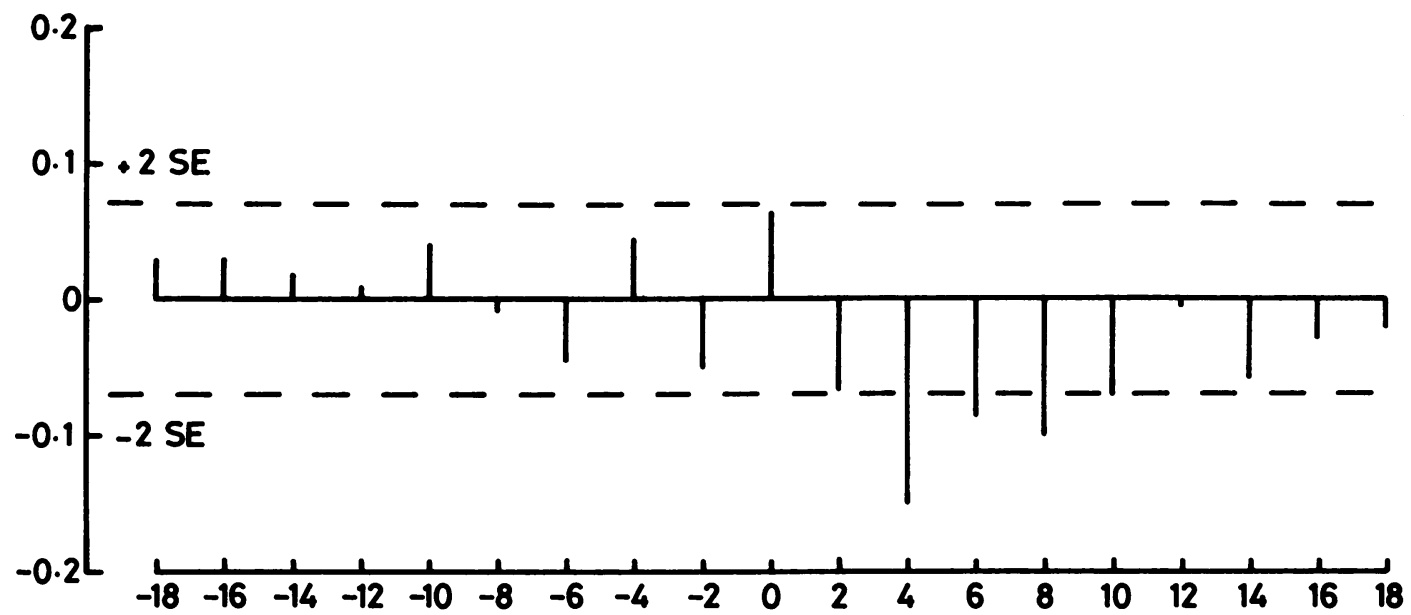

(a)

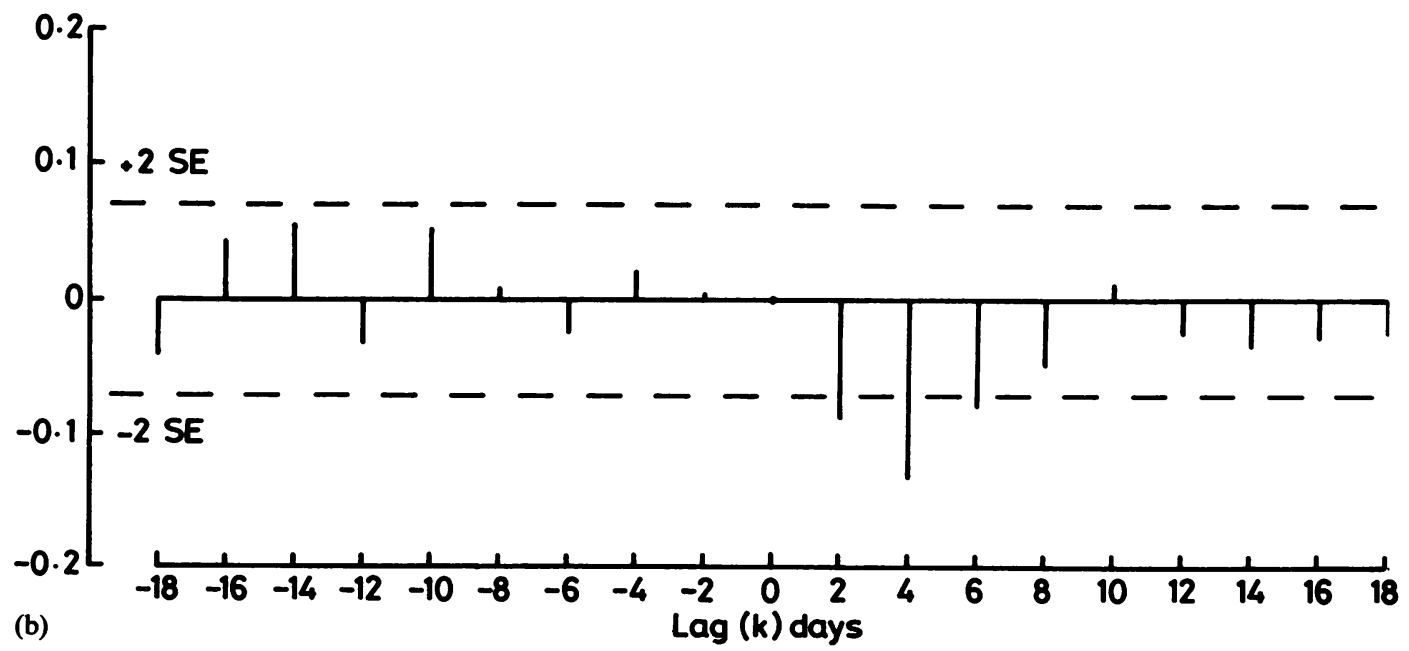

Fig 4 Cross-correlation of the residuals of (a) maximum and (b) minimum daily temperature at time (i) and total deaths at time $(i+k)$ for years 1979-83 combined 
winter than in summer. It was found during the analysis that the deseasonalised temperature was well modelled by a first order autoregression of the form $T_{t}=a T_{t-2}+e_{t}$, where $T_{t}$ is temperature at time $t$, $a$ is a constant with a value of about $0 \cdot 4$, and $e_{t}$ is the residual term at time $t$. These residual terms were significantly negatively correlated $(p<0.01)$ with deaths at lag four days. Thus the overall model of the relation between deaths and temperature is of the form $D_{t}=b_{0}+b_{1}\left(T_{t-4}-0.4 T_{t}-6\right)$ where $b_{1}$ is a coefficient significantly less than zero. This result can be rewritten as $D_{t}=b_{0}+b_{1}\left(T_{t-4}-T_{t-6}\right)+0.6 b_{1} T_{t-6}$. Thus the deaths depend on both the change in temperature and the level it reaches four to six days earlier. However, since temperature is continually fluctuating, it is impossible to separate out whether it is a change to a low temperature, or the low temperature itself, that causes the increase in deaths.

The table shows the temporal relation between the annual cycles for temperature and deaths for each year separately. The numbers in the table represent the dates of the fitted peaks of the deaths at different ages and the dates of the troughs of the maximum, minimum, and mean daily temperatures. It can be seen that in all cases the peak of the daily deaths precedes the trough of minimum daily temperature (and unusually the trough of the maximum and mean as well). The death cycle usually peaks at the beginning of January whereas the lowest temperatures usually occur towards the end of the month. It is also the case that the peak of early deaths (under 3 months) usually precedes the peak of later deaths ( 3 months to 1 year).

Although not shown here, the results of the crossspectral analysis showed good agreement with that provided by harmonic analysis. An annual cycle showed the best fit to the data and the peak of deaths preceded the troughs of maximum, minimum, and mean temperature at all ages at death, the peak of deaths at younger ages preceding that for older ones.

\section{Phase analysis from the harmonic model}

Dates of peaks of deaths and troughs of temperature for each year are shown separately. For each year days are numbered consecutively $1-365$, thus in column $1: 6=6$ January 1979 , in column 5: $33=2$ February 1983.

\begin{tabular}{lccccc}
\hline & 1979 & 1980 & 1981 & 1982 & 1983 \\
\hline $\begin{array}{l}\text { Deaths peak } \\
\text { (age 0-12 weeks) }\end{array}$ & 6 & 10 & 18 & 8 & 16 \\
$\begin{array}{l}\text { Deaths peak } \\
\text { (age 12 weeks-1 year) }\end{array}$ & 24 & 24 & 16 & 8 & 21 \\
$\begin{array}{l}\text { Total deaths peak } \\
\text { (age under 1 year) }\end{array}$ & 19 & 12 & 17 & 8 & 19 \\
$\begin{array}{l}\text { Daily minimum temperature trough } \\
\text { Daily maximum temperature trough }\end{array}$ & 27 & 28 & 22 & 28 & 33 \\
Daily mean temperature trough & 27 & 19 & 19 & 17 & 26 \\
\hline
\end{tabular}

\section{WINTER PERIOD I $98 \mathrm{I}-2$}

The results of the Knox test were non-significant over nearly all tested time and distance values. With the method of Ederer-Myers-Mantel, there was significant space-time clustering $(0.01<p<0.05)$ only $I$ for all deaths under 1 year. Using the approximate $\stackrel{\mathbb{D}}{\mathcal{D}}$ method of Knox and Lancashire, highly significant time clustering was detected irrespective of age at $\overrightarrow{\overrightarrow{\vec{F}}}$ death when a time-window of four weeks was used. $\stackrel{?}{?}$ When the data for the winter of 1981-2 were examined by taking out a quadratic trend from both series and 흘 looking for residual correlation of the daily deaths, $\frac{\bar{s}}{\vec{D}}$ rainfall, and sunshine, the results were uniformly not $\stackrel{\square}{\square}$ significant.

\section{Discussion}

The results of our time-series analysis support a direct relation between change in temperature and the occurrence of SIDS. Although it is disputed whether the winter excess of SIDS is mainly due to fluctuations in deaths at older ages ${ }^{512-20}$ nearly all studies have $\overrightarrow{-}$ shown an excess at all ages combined, producing a $\mathscr{\omega}$ predictably strong correlation with low temperature. 을 However, causality cannot be inferred from such findings unless account is taken of other explanatory covariables. While previous attempts have been ma\& to separate out the effects of temperature and viri disease, ${ }^{21} 22$ the problem of confounding factors w $\vec{\oplus}$ highlighted in a study which used cross-spectr analysis to show that not only temperature but also a variety of indicators of atmospheric pollution exhibited pronounced seasonal variation. ${ }^{23}$

Our results indicate a close inverse relation between both fall in temperature, the level it reaches, and SIDS $\frac{\circ}{\square}$ after removal of the dominant seasonal trend in the data. We do not believe that any other variable previously hypothesised to be of interest (including diagnostic bias) is likely to follow the pattern of temperature throughout the year so closely that it would mimic the modest but highly significant $\stackrel{\circ}{\circ}$ negative correlation we have demonstrated. Why then? do both phase analyses show that the peaks of deaths usually precede the temperature troughs by an interval of two or more weeks? This is approximately equivalent to the interval between the date of onset of the severe weather conditions in the winter of 1981-2을 and the time when they reached their worst and, as fig $?$ 1 shows, is probably fairly constant from year to year. Thus the peak of SIDS deaths occurs close to the timeN when the weather is deteriorating most dramatically. $N$ That the peaks of the young deaths usually occuro slightly closer to those times than do the older deaths $\omega$ may indicate greater developmental sensitivity among the younger infants. In contrast, Hoppenbrouwers $e t$ $a l^{23}$ found a coincidence of temperature troughs and 
SIDS peaks, but they present insufficient data fully to evaluate their findings.

Several studies have suggested a relation with temperature or other aspects of climate, although the findings are far from consistent. ${ }^{12} 131520-27$ A number of mechanisms have been proposed, usually invoking the effects of sudden chilling rather than sustained low temperature. These mechanisms include a direct physiological 'diving reflex' activated perhaps by cold on the infant's face, ${ }^{28}$ dehydration through sudden alterations of relative humidity, ${ }^{12}$ and increased susceptibility to apnoeic attacks in the premature and developmentally sensitive prompted by cold ${ }^{29}$ or, at the opposite extreme, overheating. ${ }^{30} 31$ It has been suggested that various deficiency states, for example, vitamin $\mathrm{D},{ }^{25}$ may play a role. More simply, the usual increase in respiratory infection with a drop in temperature, because of either increased prevalence and exposure to the organisms or increased susceptibility, has also been put forward. ${ }^{32-34}$ Overheating might arise because parents are concerned about the ambient temperature in winter, leading to increased 'tucking in' or 'sweating out' an existing infection. ${ }^{35} 36$ Support for this view is apparent in the high core temperatures of some SIDS infants post mortem and the circumstances in which some were discovered. ${ }^{30} 31$ Similarly, a case-control study showed that parents of children dying from SIDS had been more cautious than controls in relation to the time their newborn infant spent outdoors and attempted to maintain higher temperatures within their houses. ${ }^{25}$

Our findings provide little support for the hypothesis that epidemic viral infection is associated with the marked seasonal fluctuation of the condition, however. Thus at the time of the 'epidemic' of SIDS there was no apparent increase in the general level of viral disease, and 'epidemicity', defined in terms of space-time clustering, was not detected; the Knox test showed little evidence of a consistent pattern, and the positive result of the Ederer-Myers-Mantel test is interpretable in terms of the test's sensitivity to simple time clustering, which was independently demonstrated. At least six previous studies have reported the results of testing SIDS cases for spacetime epidemicity using both the above and other methods. All have been negative. ${ }^{12} 2137-40$ Several studies $^{12132427}$ have also tested for simple time clustering using a variety of different methods at different ages at death, and applied within and across seasonal cycles. The predominant finding has been positive clustering, but given the markedly seasonal distribution of the cases this is predictable. Although there is a variety of evidence that low grade infection may be implicated in some (perhaps older) cases of SIDS in terms of symptoms, the temporal relation to epidemics, ${ }^{41}$ and viral isolation at necropsy, ${ }^{42}$ we feel that repeated demonstrations of the absence of epidemicity using the above techniques, despite the fact that they are somewhat insensitive, ${ }^{43}$ weigh against the hypothesis of the importance of epidemic infection. However, we do not exclude the possibility that seasonal temperature change may influence the occurrence of SIDS by increasing susceptibility to endemic levels of viral infection, or allowing commensal overgrowth and toxin production, ${ }^{44}$ and indeed such mechanisms may best explain the two to six day lag that we have demonstrated. Overheating, too, could play a part, through parental overreaction to the environmental temperature, whether or not the child is ill.

Account must be taken of two limitations of our study of SIDS and temperature data. The first is the question of case definition and the validity of SIDS as a certification entry. Numerous studies have shown that a considerable proportion of deaths attracting the label SIDS, when subjected to a second assessment or more detailed post mortem examination, may not sustain this diagnosis. The main explanation that has been put forward is the difficulty of diagnosis by exclusion when this requires detailed post mortem studies. Yet nearly all SIDS deaths in England and Wales are certified by the coroner, whose prime concern is to investigate and exclude violent or unnatural causes of death. ${ }^{45}$ Commentary on official statistics has long recognised overuse of the term SIDS,${ }^{4}$ though not to the extent suggested recently. ${ }^{46}$ While an unknown proportion of the SIDS mentions used in our analysis will have been false positives, and some true SIDS cases will have been omitted, we think it is unlikely that the consistency of our results over five seasonal cycles can be explained by the diagnostic bias of certifiers confronting infant deaths soon after a fall in temperature.

The second limitation of the study arises from the nature of the temperature data used. To what extent are daily temperatures, recorded outdoors in central London, a valid representation of the indoor and outdoor temperatures experienced by the SIDS infants across England and Wales? The importance of this perhaps depends on precisely which hypothetical mechanism is proposed. Outdoor temperatures probably follow the same general pattern throughout the country, but the indoor environmental temperature may be successfully buffered and controlled so as to 'uncouple' it from outdoor temperature and conditions. A recent study in this country has suggested that, in fact, indoor temperatures do fall when outdoor temperatures do so. ${ }^{47}$ More obliquely, comparisons of the geographic incidence of SIDS among climatically dissimilar communities have suggested that the incidence is 
higher in those with large seasonal temperature changes, though the results are inconsistent. ${ }^{132348}$ It has also been suggested that international variation in the abolition of marked seasonal swings in deaths at all ages as well as in infancy is dependent on a greater or lesser ability to control the indoor temperature. Judged on this basis, inhabitants of England and Wales are still subject to the vagaries of their climate within their homes. ${ }^{49}$

In conclusion, we feel that the evidence presented here convincingly supports a relation between the occurrence of SIDS and a fall in temperature. Further research to clarify this relation is needed, by casecontrol studies of the microenvironmental temperature of SIDS cases at the time of death and in the period preceding their occurrence. Meanwhile it would seem appropriate to remind parents of the wisdom of avoiding, wherever possible, both chilling and/or paradoxically overheating their infants.

We acknowledge the advice and help provided by Beverley Botting, of the Medical Statistics Division OPCS, and Clive Osmond and Andy Hall, of the MRC Environmental Epidemiology Unit, Southampton. We also thank the staff of the Medical Statistics Unit at OPCS and Lesley Brewster, Lindsey Izzard, Christina Perry, and Jan Dicks in the Department of Community Medicine and Medical Statistics, Southampton for their help in extracting the data, and for typing the manuscript.

\section{References}

${ }^{1}$ Peterson DR. Evolution of the epidemiology of sudden infant death syndrome. Epidemiologic Reviews 1980; 2: 97-112.

${ }^{2}$ Golding J, Limerick S, Macfarlane A. Sudden infant death: Patterns, puzzles and problems. Shepton Mallet: Open Books Publishing Ltd, 1985.

3 Population Trends 1983; 34: 3-4.

4 OPCS Monitor DH3 85/4. Sudden infant death syndrome, $1983-4$.

${ }^{5}$ Studies on Medical and Population Subjects no. 45. Studies in sudden infant deaths. OPCS and London School of Hygiene and Tropical Medicine. London: HMSO, 1982.

${ }^{6} \mathrm{Knox}$ EG. The detection of space-time interactions. Applied Statistics 1964; 13: 25-9.

${ }^{7}$ Ederer F, Myers MH, Mantel N. A statistical problem in space and time: do leukaemia cases come in clusters? Biometrics 1964; 20: 626-38.

${ }^{8}$ Knox EG, Lancashire R. Detection of minimal epidemics. Statistics in Medicine 1982; 1: 183-9.

${ }^{9}$ Box G, Jenkins G. Time series analysis, Forecasting and Control (revised edition). San Francisco: Holden Day, 1976.

${ }^{10}$ Dixon WJ, (ed). BMDP Statistical Software, programs P1T and P2T. University of California Press, 1983.
${ }^{11}$ Bowie C, Prothero D. Finding causes of seasonal diseases using time series analysis. Int $J$ Epidemiol. 1981, 10: 87-92.

12 Fedrick J. Sudden unexpected death in infants in the Oxford Record Linkage area: an analysis with respect to time and place. Br J Prev Soc Med 1973; 27: 217-24.

${ }^{13}$ Deacon E, O'Reilly M, Williams A. Some statistical and climatological aspects of the incidence of the sudden infant death syndrome. Aust Paediatr J 1979; 15: 248-54.

14 Wagner M, Samson-Dollfus D, Menard J. Sudden unexpected infant death in a French county. Arch Dis Child 1984; 59: 1082-7.

${ }^{15}$ McGlashan N, Grice A. Sudden infant deaths and seasonality in Tasmania 1970-76. Soc Sci Med 1983; 17: 885-8.

16 Watson E, Gardner A, Carpenter R. An epidemiological and sociological study of unexpected death in infancy in nine areas of Southern England, I Epidemiology. $\mathrm{Med} \mathrm{SCi}$ Law 1981; 21: 78-88.

${ }^{17}$ Beal S. Seasonal variation in the sudden infant death syndrome. Lancet 1978; i: 1257.

18 Goldberg J, Stein R. Seasonal variation in sudden infant death syndrome. Lancet 1978; ii: 107.

19 Farber M, Chandra V. Seasonal variation in sudden infant death syndrome. Lancet 1978; ii: 473.

${ }^{20}$ Bonser $R$, West $R$. Sudden infant death and low temperature. Lancet 1979; ii: 1379.

${ }^{21}$ Bonser R, Knight B, West R. Sudden infant death syndrome in Cardiff; Association with epidemic influenza and with temperature 1955-74. Int J Epidemiology 1978; 7: 335-40.

22 Nelson K, Greenberg M, Mufson M, Moses V. The sudden infant death syndrome and epidemic viral disease. Am Epidemiol 1975; 101: 423-30.

${ }^{23}$ Hoppenbrouwers T, Colub M, Kazuko A, Hodgman J Seasonal relationship of sudden infant death syndrome and environmental pollutants. Am J Epidemiol 1981; 113: 623-35.

${ }^{24}$ Kraus A, Steele R, Langworth J. Sudden unexpected death in infancy in Ontario: II Findings regarding season, clustering of deaths on specific days and weather. Canad J Publ Hlth 1967; 58: 364-71.

${ }^{25}$ Kraus A, Steele R, Thompson M, De Grosbois P. Further epidemiological observations on sudden unexpected death in infancy in Ontario. Canad J Publ Hlth 1971; 62: 210-8.

${ }^{26}$ Richards I, McIntosh H. Confidential inquiry into 226 consecutive infant deaths. Arch Dis Child 1972; 47: 697-706.

${ }^{27}$ Greenberg M, Nelson K, Carnow B. A study of the relationship between sudden infant death syndrome and environmental factors. Am J Epidemiol 1973; 98: 412-22.

${ }^{28}$ Steinschneider A. Possible cardiopulmonary mechanisms. In sudden death syndrome: proceedings of the second international conference on causes of sudden death in infants. Eds, Bergman A, Beckwith J, Ray C. Seattle: University of Washington Press, 1970, 131.

${ }^{29}$ Collier H. Sudden death in infancy. Lancet 1971; i: 343.

${ }^{30}$ Stanton A, Scott D, Downham M. Is overheating a factor in some unexpected infant deaths? Lancet 1980 ; i: 1054-7.

${ }^{31}$ Stanton A. Overheating and cot death. Lancet 1984; ii: 1199-1201.

32 Davey M, Reid D. Relationship of air temperature to outbreaks of influenza. Br J Prev Soc Med 1972; 26: 28-32.

${ }^{33}$ Martin A, Gardner P, McQuillin J. Epidemiology of respiratory viral infection amongst pediatric inpatients over a six year period in North East England. Lancet 1978; ii: $1035-8$. 
${ }^{34}$ Bull GM. The weather and deaths from pneumonia. Lancet 1980; i: 1405-8.

${ }^{35}$ Dallas R. Cot deaths. Br Med J 1974; iii: 347-8.

${ }^{36}$ Gillick M. Commonsense models of health and disease. $N$ Engl J Med 1985; 313: 700-3.

${ }^{37}$ Froggatt P, Lynas M, MacKenzie G. Epidemiology of sudden unexpected death in infants ('cot death') in Northern Ireland. Br J Prev Soc Med 1971; 25: 119-34.

${ }^{38}$ Bergman A, Ray C, Pomeroy M, Wahl P, Beckwith J. Studies of the sudden infant death syndrome in King County Washington. III. Epidemiology. Pediatrics 1972; 49: 860-70.

${ }^{39}$ Knox G, unpublished. Quoted in Froggatt $P$, et al, op cit.

${ }^{40}$ Brackenridge C, unpublished. Quoted in SMPS no. 45. op cit.

41 Williams A, Uren E, Bretherton L. Respiratory viruses and sudden infant death. $B r$ Med $J$ 1984; 288: 1491-3.

${ }^{42}$ Downham M, Gardner P, McQuillin J, Ferris J. Role of respiratory viruses in childhood mortality. $\mathrm{Br}$ Med $J$ 1975; i: $235-9$.
${ }^{43}$ Chen R, Mantel N, Klingberg M. A study of three techniques for time-space clustering in Hodgkin's disease. Statistics in Medicine 1984; 3: 173-84.

44 Morris JA, Haran D, Smith A. Common bacterial toxins are a possible cause of the sudden infant death syndrome. Medical Hypotheses, in press.

45 Watson E. Changes in verdict of sudden infant death. Lancet 1985; i: 631 .

${ }^{46}$ Knowelden J, Keeling J, Nicholl J. A multicentre study of post neonatal mortality. London: DHSS, 1984.

${ }^{47}$ Eiser C, Town C, Tripp J. Dress and care of infants in health and illness. Arch Dis Child 1985; 60: 465-70.

${ }^{48}$ Peterson D. Sudden unexpected deaths in infants: incidence in two climactically dissimilar metropolitan communities. Am J Epidemiol 1972; 95: 95-8.

${ }^{49}$ Hare E, Moran P, Macfarlane A. The changing seasonality of infant deaths in England and Wales 1912-78 and its relation to seasonal temperature. J Epidemiol Community Health 1981; 35: 77-82. 